\title{
Study of placental changes in pregnancy induced hypertension
}

\author{
Maimoona Ahmed*, Rekha G. Daver
}

Department of Obstetrics and Gynaecology, Grant Government Medical College and J. J. Hospital, Mumbai, India

Received: 12 September 2013

Accepted: 21 September 2013

\section{*Correspondence:}

Dr. Maimoona Ahmed,

E-mail: azulemontana@gmail.com

(C) 2013 Ahmed M et al. This is an open-access article distributed under the terms of the Creative Commons Attribution Non-Commercial License, which permits unrestricted non-commercial use, distribution, and reproduction in any medium, provided the original work is properly cited.

\begin{abstract}
Background: Study of histopathological changes in placenta in pregnancy induced hypertension (PIH).

Methods: Post delivery placentas of 130 cases were examined and findings correlated with severity of PIH.

Results: The mean placental weight was 438.9 gms, 374 gms and 333.86 gms and the mean fetal weight to placental weight ratio was 6.003:1, 5.6:1 and 5.27:1 in cases of mild, moderate and severe PIH respectively. Infarction was seen in $10.25 \%, 33.3 \%$ and $59 \%$ and calcification was present in $15.38 \%, 30 \%$ and $50 \%$ of the cases of mild, moderate and severe PIH respectively. Retroplacental clot was seen in $36.4 \%$ of severe PIH cases. The mean numbers of syncytial knots were 20.4 (mild PIH), 35.97 (moderate PIH) and 59.77 (severe PIH) and $77.27 \%$ of severe cases of PIH had $>40 \%$ areas showing trophoblastic hyperplasia.

Conclusion: PIH adversely influences the placental morphology and histopathological examination post delivery helps investigate the mechanism of placental dysfunction in detail.
\end{abstract}

Keywords: Pregnancy induced hypertension, Placenta, Histopathology

\section{INTRODUCTION}

Hypertensive disorders in pregnancy forms one part of the deadly triad, along with haemorrhage and infection, that contribute greatly to maternal and fetal morbidity and mortality. Of these, pregnancy induced hypertension $(\mathrm{PIH})$ is a pregnancy - specific syndrome that can virtually affect every organ system. It is a challenge to be addressed and overcome if there is to be any significant improvement in maternal and perinatal health.

The fetus is dependent on the placenta for maintaining and promoting normal development. In pregnancy induced hypertension, pathological changes in the placenta such as infarction, calcifications, diffuse placental thrombosis, inflammatory placental vasculopathy and abnormal trophoblastic proliferation occur resulting in reduced blood flow across placenta and uteroplacental insufficiency.

The present study analyzes the histopathologic changes in the placenta of cases of PIH, so as to provide a better understanding of the pathologic process involved.

\section{METHODS}

A prospective study was conducted over a period of one year from $1^{\text {st }}$ January 2009 till $31^{\text {st }}$ December 2009 in the Department of Obstetrics and Gynecology, Grant Medical College, Mumbai. 130 cases of pregnancy induced hypertension were studied. The cases with systolic blood pressure greater than $130 \mathrm{mmHg}$, diastolic blood pressure greater than $90 \mathrm{mmHg}$ on two measurements taken 6 hours apart, in association with proteinuria more than $300 \mathrm{mg}$ in 24 hours urine were included in the study. These cases were further divided as mild preeclampsia if the diastolic blood pressure was $\leq 100 \mathrm{mmHg}$ and as moderate preeclampsia if the diastolic blood pressure was 110 $\mathrm{mmHg}$. Severe cases were defined if the systolic blood pressure $-\geq 160 \mathrm{mmHg}$, diastolic blood pressure $\geq 110$ $\mathrm{mm} \mathrm{Hg}$ and proteinuria 3+ or more. Maternal and fetal outcome was studied and post delivery placenta was sent for histopathologic examination. Gross and microscopic examination was done and findings were correlated with the severity of PIH. Statistical analysis was carried out using Spearman's rho and the correlation considered 
significant at $\mathrm{P}<0.001$. Approval for the study was taken from the Ethics Committee.

\section{RESULTS}

Out of the total 130 cases, there were 70 cases of mild PIH, 30 moderate and 22 were of severe PIH. On gross examination (Table 1), the mean weight of placenta was 438.9 gm in mild cases of PIH, 374 gm in moderate cases of PIH and $333.86 \mathrm{gm}$ in severe cases of PIH. There is a significant negative correlation between placental weight and PIH severity (spearman's rho $=-0.403$, p<0.001) i.e. as the PIH severity increases, the placental weight decreases.

The mean fetal weight to placental weight ratio was 6.003:1 in mild cases of PIH, 5.6:1 in moderate cases and 5.27:1 in severe cases of PIH. There is a significant negative correlation between fetal weight to placental weight ratio and PIH severity (spearman's rho $=-0.659$, $\mathrm{p}<0.001)$ i.e. as the PIH severity increases, the fetal weight to placental weight ratio decreases.

The mean thickness of placenta calculated was $2.75 \mathrm{~cm}$ in mild, $2.2 \mathrm{~cm}$ in moderate and $1.99 \mathrm{~cm}$ in severe cases of
$\mathrm{PIH}$. There is a significant negative correlation between placental thickness and PIH severity (spearman's rho = $0.610, p<0.001)$ i.e. as the PIH severity increases, the placental thickness decreases.

On microscopic examination (Table 2), $10.25 \%$ of mild cases of PIH showed infarcts, whereas $33.3 \%$ and $59 \%$ of moderate and severe cases respectively showed infarction in their placentas. Calcification was present in $15.38 \%$, $30 \%$ and $50 \%$ of the cases of mild, moderate and severe $\mathrm{PIH}$ respectively. Retroplacental clot was absent in the mild cases but present in $10 \%$ of moderate PIH, while $36.4 \%$ had them in severe PIH cases. In mild cases of $\mathrm{PIH}, 7.7 \%$ had subchorionic fibrin plaques, $36.7 \%$ in moderate and $63.6 \%$ in severe cases of PIH.

The mean numbers of syncytial knots (Table 3) were 20.4, 35.97 and 59.77 in mild, moderate and severe cases of PIH respectively. Majority of the cases of mild PIH $(70 \%)$ showed $<20 \%$ areas of trophoblastic hyperplasia per low power field. $56.66 \%$ of the cases of moderate $\mathrm{PIH}$ had trophoblastic hyperplasia in $20-40 \%$ areas whereas $77.27 \%$ of severe cases of PIH had $>40 \%$ areas showing trophoblastic hyperplasia.

Table 1: Gross features of placenta in PIH $(n=130)$.

\begin{tabular}{|ll|ll|c|}
\hline Severity of PIH & $\begin{array}{l}\text { Placental weight } \\
(\text { Gm) }(\text { Mean } \pm \text { SD) }\end{array}$ & $\begin{array}{l}\text { Fetal weight/Placental } \\
\text { weight ratio }\end{array}$ & $\begin{array}{l}\text { Thickness of placenta } \\
(\mathbf{C m})(\text { Mean } \pm \text { SD) }\end{array}$ & Total \\
\hline Mild & $438.9 \pm 66.15$ & $6.003: 1$ & $2.75 \pm 0.34$ & 78 \\
\hline Moderate & $374 \pm 87.59$ & $5.61: 1$ & $2.2 \pm 0.43$ & 30 \\
\hline Severe & $333.86 \pm 120.53$ & $5.27: 1$ & $1.99 \pm 0.49$ & 22 \\
\hline
\end{tabular}

Table 2: Histopathological Changes in placenta in PIH $(n=130)$.

\begin{tabular}{|llllll|}
\hline Severity of PIH & Infarcts & Calcification & $\begin{array}{l}\text { Retro-placental } \\
\text { Clot }\end{array}$ & $\begin{array}{l}\text { Subchorionic Fibrin } \\
\text { Plaques }\end{array}$ & \begin{tabular}{c} 
Total \\
\hline Mild
\end{tabular} \\
\hline Moderate & $10(33.3 \%)$ & $9(30 \%)$ & $3(10 \%)$ & $11(36.7 \%)$ & 78 \\
\hline Severe & $13(59 \%)$ & $11(50 \%)$ & $8(36.4 \%)$ & $14(63.6 \%)$ & 30 \\
\hline Total & 31 & 32 & 11 & 31 & 22 \\
\hline
\end{tabular}

Table 3: Changes in placental villi in PIH ( $n=130)$.

\begin{tabular}{|llllll|}
\hline $\begin{array}{l}\text { Severity of } \\
\text { PIH }\end{array}$ & $\begin{array}{l}\text { No. of syncytial } \\
\text { knots (mean) }\end{array}$ & \multicolumn{2}{l}{ Trophoblastic hyperplasia (per low power field) } & Total \\
\hline Mild & 20.4 & $70(89.7 \%)$ & $7(8.9 \%)$ & $1(1.2 \%)$ & 78 \\
\hline Moderate & 35.97 & $10(33.33 \%)$ & $17(56.66 \%)$ & $3(10 \%)$ & 30 \\
\hline Severe & 59.77 & 0 & $5(22.7 \%)$ & $17(77.27 \%)$ & 22 \\
\hline
\end{tabular}




\section{DISCUSSION}

The foetus, placenta and mother form a composite triad of dynamic equilibrium, and dysfunction of any one of them can affect the other. Thus the present study aims to correlate the changes seen in placenta in cases of PIH.

Normally a placenta weighs from 400 gms to 800 gms. In the present study, the mean placental weight was $438.9 \mathrm{gms}$ in mild PIH, $374 \mathrm{gms}$ in moderate cases and 333.86 gms in severe cases. A significant negative correlation was calculated between the placental weight and severity of PIH. Thus we can see that the weight of placenta decreases with the increasing severity of the disorder. These findings corroborate with the studies of other workers Damania et al in $1989^{1}$, Fox et al in $1994^{2}$ and Kalousek et al in 1994. ${ }^{3}$ At term the fetoplacental ratio varies between 6:1 and 8:1 (Morrison, 1963). In our study, the fetal weight to placental weight ratio was 6.003:1 in mild cases of PIH, 5.6:1 in moderate cases and 5.27:1 in severe cases of PIH. There is also a significant negative correlation between the ratio and severity of PIH indicating that as the severity of PIH increases the ratio decreases. These findings were also seen in study by Bandana Das et al in 1996 where the ratio was 6.15:1 in mild cases of PIH and 5.43:1 in severe cases. ${ }^{4}$

Also another study by Kher Zawar et al in 1981 comes to the same conclusion. ${ }^{5}$

The present study noted that the mean thickness of placenta calculated were $2.75 \mathrm{~cm}$ in mild, $2.2 \mathrm{~cm}$ in moderate and $1.99 \mathrm{~cm}$ in severe cases of PIH. A significant negative correlation was found between the thickness of placenta and PIH severity. Hence, the placentas of more severe cases of PIH are thinner as compared to the milder cases. This has also been substantiated by the study by Bandana Das et al. ${ }^{4}$

On microscopic examination, in the present study, $10.25 \%$ of mild cases of PIH showed infarcts, whereas $33.3 \%$ and $59 \%$ of moderate and severe cases respectively showed infarction in their placentas. Similar finding was noted by Bandana Das et al in 1996 where they showed an increased finding of infarction in cases of $\mathrm{PIH} .{ }^{4}$ Udainia et al in 2004 had also observed an increase in the incidence of placental infarction with severity of toxaemia. ${ }^{6}$ Naeye and Friedman in 1979 calculated that $70 \%$ of the excess foetal deaths in women with hypertension are due to large placental infarcts and markedly small placental size. ${ }^{7}$

Calcification was present in $15.38 \%, 30 \%$ and $50 \%$ of the cases of mild, moderate and severe PIH respectively in our study. Mohan et al in $1989^{8}$ and Bandana Das et al in $1996^{4}$ also found higher incidence of calcification in placenta of PIH cases however this did not alter the fetal outcome.
In our study, retroplacental clot was absent in the mild cases but present in $10 \%$ of moderate $\mathrm{PIH}$, while $36.4 \%$ had them in severe PIH cases. Fox in $1995^{9}$ and Mohan et al in $1989^{8}$ reported higher incidence of retroplacental hematoma in pre eclampsia. According to Bandana Das et al in 1996, the presence of Retroplacental hematoma was associated with low Apgar score babies larger hematoma was also associated with intrauterine fetal death, because a considerable portion of the villi are acutely separated from the maternal utero placental circulation. They have also showed an increase in the subchorionic fibrin plaques in PIH which has been found in the present study. ${ }^{9}$ Increase in placental infarcts, retroplacental hematoma and calcification was also noted in the study by Sodhi S et al in 1990 and these findings correlated well with the severity of maternal disease. ${ }^{10}$

The present study shows the mean number of syncytial knots to be 20.4, 35.97 and 59.77 in mild, moderate and severe cases of PIH respectively. Thus the number of syncytial knots increased with increasing severity of PIH.

Majority of the cases of mild PIH (70\%) showed <20\% areas of trophoblastic hyperplasia per low power field. $56.66 \%$ of the cases of moderate PIH had trophoblastic hyperplasia in $20-40 \%$ areas whereas $77.27 \%$ of severe cases of PIH had $>40 \%$ areas showing trophoblastic hyperplasia. Genset in 1992 reported that cytotrophoblastic hyperplasia and excessive syncytial knot formation are seen in hypertensive disorders of pregnancy as invariable results of overall reduction of foetal perfusion of the placenta. $^{11}$ An increase in the proliferation of cytotrophoblasts was also reported in a study by Kurdukar et al in 2007. The changes were directly proportional to the severity of disease and perinatal outcome was worse with advancing grades of PIH. These vascular villous lesions were considered secondary to uteroplacental ischemia. ${ }^{12}$

In a study by Majumdar $\mathrm{S}$ et al in 2005, placentae of normotensive patients were compared with those of hypertensive patients and similar findings were documented. ${ }^{13}$ Such comparative studies were also done by Aparna $\mathrm{N}$ et al in 2011 and they concluded that gross abnormalities and villous lesions were significant in placentae of normotensive patients. ${ }^{14}$

Thus from the present study it can be concluded that, hypertensive disorders of pregnancy such as pregnancy induced hypertension adversely influence the morphology of the placenta and sending placenta for histopathological examination will help investigate the mechanism of placental dysfunction in detail. If this mechanism is fully elucidated, more precise intervention strategies can be devised and can contribute to more effective therapies in the future.

Funding: None

Conflict of interest: None declared

Ethical approval: The study was approved by the Institutional Ethics Committee 


\section{REFERENCES}

1. Damania KR, Salvi VS, Ratnaparki SK, Daftari SN. The placenta in hypertensive disorder in pregnancy. J Obst and Gynaecol Ind 1989;39:28-31.

2. Fox, $\mathrm{H}$; The placenta in intra uterine growth retardation. In Ward RHT, Smith SK, Donnai D (Eds). Early foetal growth and development. RCOG Press, London, 1994; Pp : 223 -235.

3. Kalousek DK, Langlosis S. The effects of placental and somatic chromosomal mosaicism on foetal growth. In: Ward RHT, Smith SK, Donnai (eds), Early foetal growth and development, RCOG Press, 1994;Pp 245-256.

4. Bandana Das, D. Dutta, S. Chakraborthy, P. Nath. Placental morphology in hypertensive disorders of pregnancy and its correlation with fetal outcome. J Obstet and Gynecol India, 1996; 46(1) :40-46.

5. Kher AV, and Zawar MP, et al. Study of placental pathology in toxaemia of pregnancy an distal fetal implications. Indian $\mathbf{J}$ Pathol Microbiol 1981;24:245-251.

6. Udainia A, Bhagwat SS, Mehta CD. Relation between placental surface area, infarction and foetal distress in pregnancy induced hypertension with its clinical relevance. J Anat Soc Ind 2004, 53; 1: 27-30

7. Naeye RL, Friedman EA.Causes of perinatal death associated with gestational hypertension and proteinuria. Am J Obst \& Gynaecol,1979; 133: 8 11

8. Mohan Harsh, Sodhi S, Mohan PS, et al. Fetal correlation with placental pathology in toxaemia of pregnancy. J Obstet and Gynecol India 1989; 39 : 170-75

9. Fox H. General Pathology of placenta. Obstetrics and gynaecological Pathology ed. New York: Churchill Livingstone;1995 .page 1477-1508.

10. Sodhi S, Mohan H, Jaiswal TS, Mohan PS, Rathee S. Placental pathology in pre-eclampsia eclampsia syndrome. Indian J Pathol Microbiol Jan 1990;33(1):11-6.

11. Genset DR. Estimating the time of death of stillborn foetuses-II. A study of 71 stillborns. B J Obst Gynaecol 1992; 80: 585 - 592.

12. Kurdukar MD, Deshpande NM, Shete SS, Zawar MP. Placenta in PIH. Indian J Pathol Microbiol. 2007 Jul; 50(3):493-7.

13. Majumdar S, Dasgupta $H$, Bhattacharya $K$, Bhattacharya A. A study of placenta in normal and hypertensive pregnancy. $\mathbf{J}$ Anat Soc India. 2005;54(2):1-9.

14. Aparna Narasimha, Vasudeva DS. Spectrum of changes in placenta in toxaemia of pregnancy. Indian Journal of Pathology and Microbiology March 2011;54(1):15-20.

DOI: $10.5455 / 2320-1770.1 j \mathrm{rcog} 20131207$

Cite this article as: Ahmed M, Daver RG. Study of placental changes in pregnancy induced hypertension. Int J Reprod Contracept Obstet Gynecol 2013;2:524-7. 